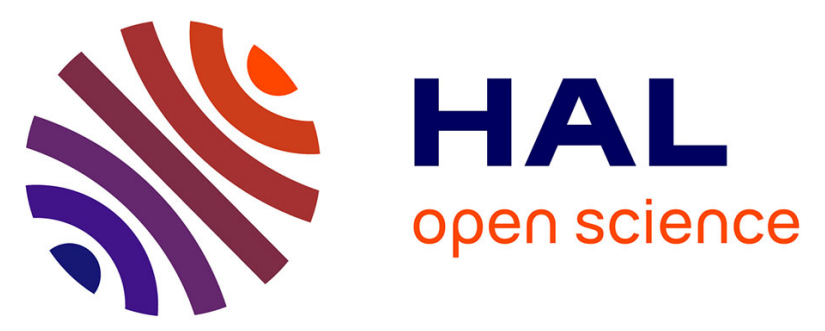

\title{
Multi-point opacity measurement in a fire environment using a network of optical fibres
}

\author{
G. Parent, R. Morlon, P. Fromy, E. Blanchard, Pascal Boulet
}

\section{To cite this version:}

G. Parent, R. Morlon, P. Fromy, E. Blanchard, Pascal Boulet. Multi-point opacity measurement in a fire environment using a network of optical fibres. Fire Safety Journal, 2016, 83, pp.7-14. 10.1016/j.firesaf.2016.04.003 . hal-01446763

\section{HAL Id: hal-01446763 \\ https://hal.univ-lorraine.fr/hal-01446763}

Submitted on 10 Oct 2018

HAL is a multi-disciplinary open access archive for the deposit and dissemination of scientific research documents, whether they are published or not. The documents may come from teaching and research institutions in France or abroad, or from public or private research centers.
L'archive ouverte pluridisciplinaire HAL, est destinée au dépôt et à la diffusion de documents scientifiques de niveau recherche, publiés ou non, émanant des établissements d'enseignement et de recherche français ou étrangers, des laboratoires publics ou privés.

\section{(ㅇ)(1) $\$$}

Distributed under a Creative Commons Attribution - NonCommercial - NoDerivatives| 4.0 


\title{
Multi-point opacity measurement in a fire environment using a network of optical fibres
}

\author{
G. Parent (1), R. Morlon (1,2), P. Fromy (2), E. Blanchard (2), P. Boulet (1)* \\ (1) LEMTA, Université de Lorraine, CNRS \\ 2 Avenue de la Forêt de Haye TSA 60604 - 54518 Vandœuvre lès Nancy Cedex, France \\ (2) CSTB - Centre Scientifique et Technique du Bâtiment \\ 84 avenue Jean Jaurès - Champs sur Marne - 77447 Marne-La-Vallée cedex 2, France. \\ *Cor. author : Tel (33) 383595574 - pascal.boulet@univ-lorraine.fr
}

\begin{abstract}
Opacity measurements were carried out in a smoke layer using a light source and photodiodes located outside the hot environment, using a network of optical fibers to transport the incident and attenuated light. The whole system was designed with protections for the emission and reception points against smoke, droplets and water vapor generated by a water mist system. It was tested first in laboratory conditions in order to assess its stability at high temperature or in a water spray. Its accuracy regarding the transmission measurement was then evaluated using a reference material. It was used after these qualifications steps in a fire smoke layer flowing along a corridor roof, in order to provide a stratification profile based on transmittance data. Results were compared to the stratification data obtained with classical thermocouple measurements. The analysis showed similar conclusions without spray: the vertical evolution in temperature and transmission indicated a similar smoke-free layer, around $1.20 \mathrm{~m}$ high in the $2.40 \mathrm{~m}$ high corridor when smoke was produced by a $250 \mathrm{~kW}$ heptane pool fire in a neighboring room. When studying smoke/mist interactions using a nozzle injecting water in the corridor, a perfect mixing was deduced from temperature measurements, while some discrepancies still appeared with the opacimeters, indicating some variations in the particle concentrations. The opacity could serve to predict these concentration profiles and the visibility in the smoke/droplet medium.
\end{abstract}

KEY WORDS: opacity, transmission, visibility, smoke, water spray, stratification 


\section{INTRODUCTION}

When a fire is burning in an enclosure, for a wide range of compartment fires, there is an obvious difference between an upper layer filled with smoke and a lower layer constituted of fresh air. The smoke layer is hot and opaque whereas the smoke-free layer is cold, heavier and quite transparent. These stratification phenomena are widely investigated for fire propagation and safety studies. In this frame, temperature measurements using thermocouple trees are often involved in experimental campaigns [1]. Such measurements are easy, cheap and can be obtained in confidence. The estimation of the measurement uncertainty in parallel is also easy with this instrumentation. The data analysis quickly leads to the smoke layer thickness and its evolution. Indeed, the temperature vertical variation is generally contrasted between the hot smoke and the fresh air in the free-smoke area. Correlations exist to estimate a smoke-free layer height based on this variation. We can cite the so-called N\% rule by Cooper [2], the model by Quintiere et al. [3] and Janssens and Tran [4] considering temperature integrals and the models by He et al. [5]. Even if these relationships were initially developed to predict mass flows through openings or to compare experiments with two-zone model predictions, they are still used nowadays, in particular to render an idealized representation of the fire where two layers are observed. For instance, the well known CFD code Fire Dynamics Simulator (FDS) uses the model by Janssens and Tran [4].

Beside the thermal effects associated to the smoke, its opacity is of interest in fire safety. Smoke includes soot particles in suspension which induce absorption and scattering phenomena and attenuate the visible light. Smoke opacity affects the visibility for any people supposed to escape from the fire area. Thus, smoke opacity is an interesting quantity to qualify people escape conditions. It can be linked to the visibility or to characteristic extinction coefficients through simple relationships, as found in [6] for example, from the pioneering works by Jin [7], Rasbach [8] or Babrauskas [9] among others. In particular the well-known relationship by Jin links the visibility to the inverse of the extinction coefficient of the smoke. Similarly, the relationships between the extinction coefficient and the opacity can be used to characterize the smoke density in some standardized tests $[10,11]$.

22 In fire tests, smoke opacity is hardly measured whereas it provides another way to study smoke production and track its flow. Opacity is frequently deduced by measuring the amount of light transmitted along an optical path with BeerLambert's law. For instance, we can cite the references $[12,13]$ in which a wide spectrum band emitter was used to study fire at the compartment scale. We can also cite Barakat et al. [14] who used monochromatic beams in the visible range to study smoke produced by different fire loads and to assess its extinction properties as a function of wavelength. The approximation based on the Beer-Lambert's law omits multiple scattering phenomena. It can be correct for smoke owing to the moderate particle size and concentration. The exponential form of this law leads to express the smoke characteristics in terms of the optical density equal to the natural logarithm of the transmittance through the smoke layer. The particles in smoke are consequently investigated with this measurement method combined with models for the attenuation properties. The scattering may start to be more important when considering droplets in suspension. Then, the basic relationships based on the Beer-Lambert's law may become inaccurate, unless a collimated beam is considered, with detection in a very 
narrow angle and considering an extinction coefficient for the attenuation property (which involves both absorption and scattering). In this case, the opacity is expected to provide an information on the visibility, affected by both the smoke and the droplets simultaneously.

Our research is partly dedicated to study the interaction phenomena between water spray and smoke flow. The objective is to assess the impact of water sprays on the smoke observing modifications in the temperature and the opacity in the visible spectrum range. The practical objective is to assess the impact of water sprays on people evacuation conditions. We also compare different technologies, among them conventional sprinkler systems generating large droplets with high water flow rate under low operating pressure and more recent water mist systems which are spreading water into a cloud of very small droplets. Such a research requires real scale tests and our study is based on a fine description of the thermal and optical environment (see Ref. [15]). The idea is to install trees of usual thermocouples and also trees of opacimeters to get simultaneous vertical evolutions. However, the induced environment in the fire tests is particularly harsh since opacimeters are placed in hot gases transporting soot and water vapor. Moreover, when the spray is activated, there is a large amount of water droplets both in suspension or directly sprayed in the opacimeter direction. Thus, in addition to thermal effects, opacimeters are subjected to soot deposition, water vapor condensation and also water droplet deposition. Usual opacimeters are not designed for operating in such conditions. In particular, photodiodes and even more laser diodes are very sensitive to temperature and do not operate at high temperature. In this context, a new opacimetry system was developed for the present study, which is able to operate in the fire environment, even if a spray system is activated. The present paper describes the design of the opacimeters, the evaluation of their performances at laboratory scale and their application to real scale fire tests where smoke/spray interactions are studied. In that frame, the real scale experimental setup is described and the experimental results are presented. Moreover, the smoke stratification is discussed based on temperature and opacity. In other words, the data provided by both measurement methods are compared.

\section{PRINCIPLE OF THE OPACIMETERS INVOLVING THE OPTICAL FIBER NETWORK}

In a previous work [15], the transmittance measurement was based on the attenuation of a laser beam at wavelength $635 \mathrm{~nm}$. The device involved a laser diode used for the beam generation and a photo-diode used as a detector located at $10 \mathrm{~cm}$ from the diode on the line of sight. The photodiode converted the amount of transmitted light in voltage signal. Laser diodes and detectors were each protected by a small box with a hole for the laser beam path in order to avoid any droplet deposit on the optical surfaces. All the laser diodes and photodiodes were supplied with batteries located inside the protection boxes. This installation was practical and cheap. However, several problems were encountered, which did not allow a smoke characterization in confidence during fire. First, laboratory tests showed that both the selected photodiode and laser diode cannot be used with full confidence above $50^{\circ} \mathrm{C}$, especially because the laser diode is very sensitive to temperature and even becomes faulty if the temperature is too high. That is why laser diodes are often used with a thermoelectric cooler in order to get a stable emission. Secondly, a deposit of soot and droplets was also suspected. We 
concluded that a false attenuation may be measured if all these problems are not solved.

2 This conclusion guided us toward a system involving a source and a receptor protected from the harsh environment. First of all, it was decided to use a light source located outside the high temperature area, using optical fibers to guide the incident light toward the measurement area. Similarly the light collected after the crossing through the medium (smoke and/or droplets) is transported outside the harsch environment via optical fibers up to a photodiode. Some collimators are used both in order to obtain a collimated laser beam at the exit of the fiber that brings the light inside the medium and to focuse the beam inside the fiber which carries the collected light to the photodiode. The collimators lenses have to be protected from the deposit of soot and water droplets and from water vapor condensation (the air is very wet due to water vapor contained in smoke and due to the evaporation of the spray). In order to avoid this, the collimators are put at the end of small tubes (70 $\mathrm{mm}$ long) which are encapsulated in a pressurized protection box.

1 In other words, the opacity measurement involves a light source and a detector as usual, but the basic idea in the present work is to use an optical fiber network in order to avoid the perturbation of the light source by the hot environment loaded with small particles and humidity generated by the smoke-spray mixing. This is illustrated in Figure 1 with a schematic view on the left and a picture of the setup on the right. A fiber-coupled laser source (Thorlabs MCLS1) at $642 \mathrm{~nm}$ is used. The temperature of the laser diode is controlled with a Peltier device in order to warrant a signal stability at $+/-0,02 \%$. The signal is splitted by using 1x4 single mode couplers in cascade in order to provide 16 different signals in parallel. Each signal is guided with an optical fiber especially chosen for a possible use at high temperature toward the emission the experiment to check the good stability of the device. The ratio between the voltage registered during the experiment and the reference signal yields a transmittance as a function of time.

\section{OPACIMETER QUALIFICATION AT LABORATORY SCALE} box, with a lens allowing the collimation of the incident light. A variable path line through the smoke/droplet mixing is possible between $10 \mathrm{~cm}$ and $30 \mathrm{~cm}$. The emission and the reception boxes are set on the same metallic support: a bar with a section of $2 \mathrm{~cm} \times 2 \mathrm{~cm}$ to allow a correct and stable alignment. As explained before, an air blowing device is used in order to prevent from droplets, soot and water vapor in excess flowing inside the box. The measurement itself is a voltage signal delivered by the photodiodes between 0 and $10 \mathrm{~V}$. The reference signal is measured before the fire ignition and after

This device was first qualified through laboratory tests in two configurations. The aim was to check the stability of the measured signal when submitted to thermal stresses and then to an air/droplet environment.

The thermal test was conducted with an oven. The emission device and the receptor on their metallic support were submitted to heating and cooling cycles. Figure 2 shows the registration of the voltage at the receptor during a typical test for temperature increasing above $200^{\circ} \mathrm{C}$, which is the maximum temperature expected in our experiment. As can be seen a slight deviation with a maximum value of $3.1 \%$ was observed, which provided an information on the related uncertainty in case of measurement during a temperature varying step. However, this was the maximum deviation and the signal always 

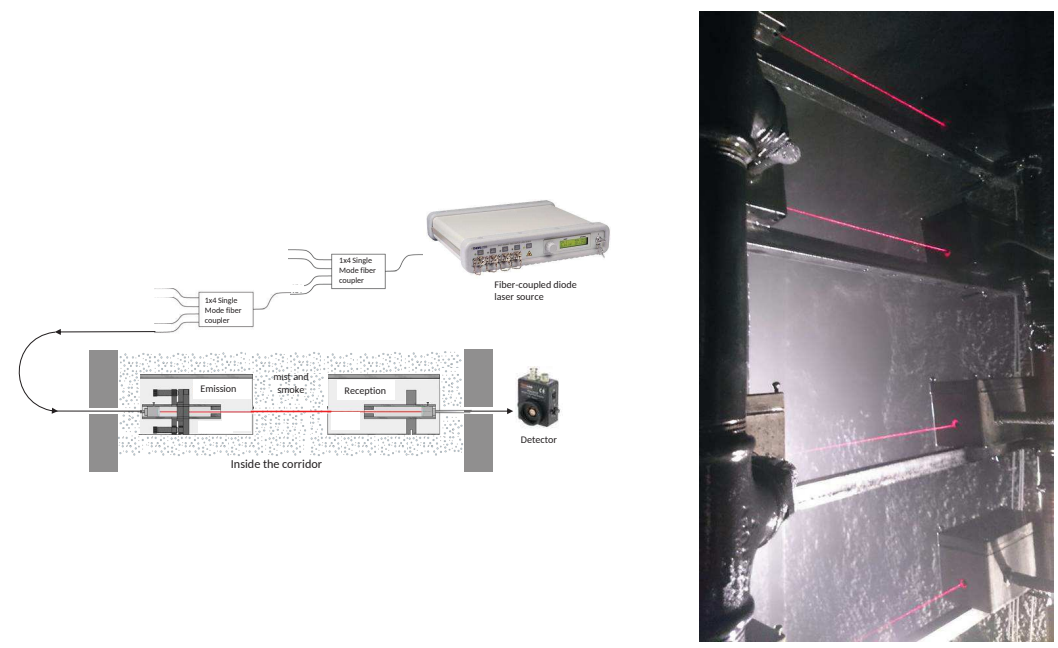

(a) Schematic view

(b) Picture of the opacimetry ssytem

Figure 1. Schematic view of the opacimeter network. Dimensions of boxes (length $20 \mathrm{~cm}$, width $7 \mathrm{~cm}$ and height $7 \mathrm{~cm}$ ) are not respected as compared to the corridor width. Picture of the setup on the right subfigure.

1 came back to its reference value ( $9 \mathrm{~V}$ in the presented case). Moreover the signal was observed to be only affected for 2 temperatures higher than $150^{\circ} \mathrm{C}$, it was almost stable for lower temperatures.

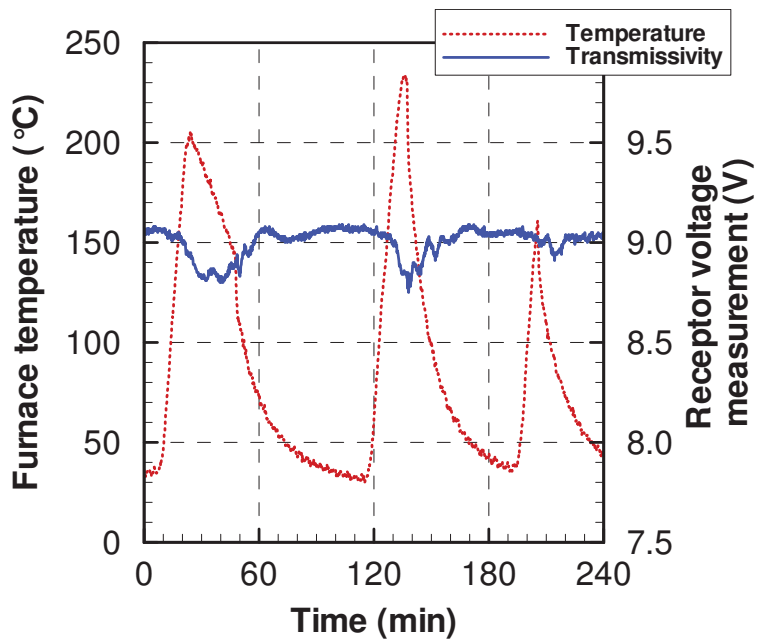

Figure 2. Test of the opacimeter under thermal stress

3 The behaviour in a medium loaded with droplets was then checked submitting the opacimetry system to a water mist 
generated with a series of nozzles feeded with water at 4 bars on two feeding horizontal ramps, one above the opacimeter with a downward injection and the second below the opacimeter with an upward injection, such that the opacimeter was submitted to droplet sprays from all directions. A series of TP400067 nozzles (from Spraying systems and Co.) were used, with nominal flow rate equal to $0.32 \mathrm{~L} / \mathrm{min} /$ nozzle generating droplets with a mean Sauter diameter around $100 \mu \mathrm{m}$. Such fine droplets were selected owing to their ability to reach any hidden area in the measurement volume, possibly reaching the opacimeters despite the protection box encapsulating the receptor. Figure 3 shows the registration of the voltage at the receptor during a typical test. On the left (Figure 3a), the opacimeter was only encapsulated in a box, preventing from direct aspersion. The transmittance is given as a function of time. The sharp decreases correspond to the spray operation periods. The signal re-increased when the spray was stopped, but it did not reach the target value of 1 which should be the reference value through air without spray. The reference even further decreased with time. This was attributed to water vapor condensation on the collimator lenses. An air blowing system was designed in order to avoid this condensation. Air was introduced in the box with a very small pipe from a pressurized air tank. The air flow rate was set to a very low level in order to avoid any perturbation outside the box, but it was high enough to prevent from the flow of very small droplets inside the box. The air flow was also dry enough to avoid condensation. Moreover, this relatively fresh air is expected to cool down the emission and reception boxes in case of use in a hot environment. Figure $3 \mathrm{~b}$ clearly demonstrates that the signal level after the spray stop was recreasing up to a transmissivity of 1 and that the problem was solved with the present 1 system.

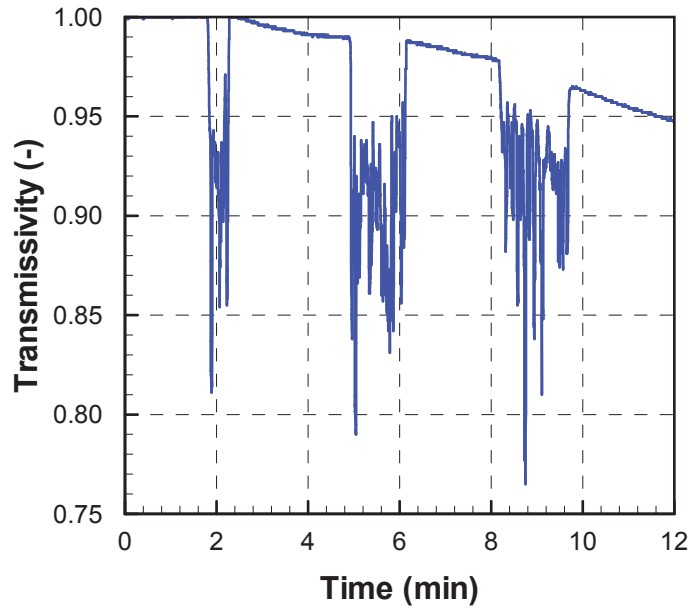

(a) Without air blowing

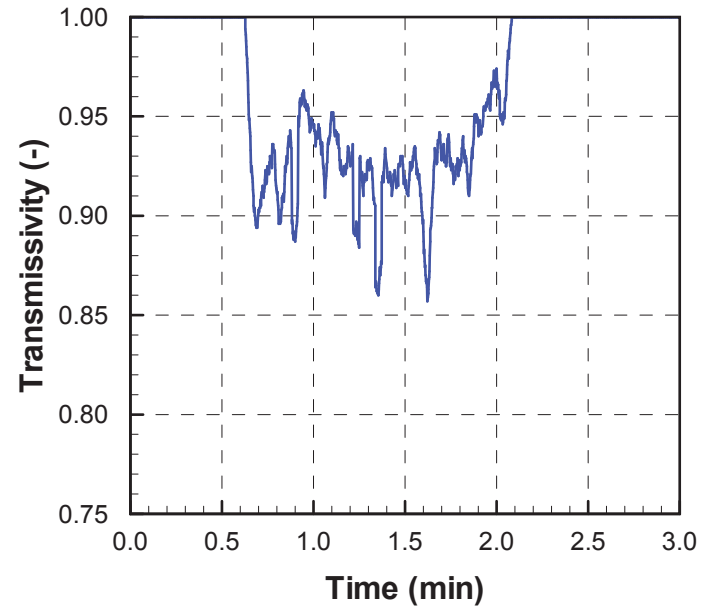

(b) With air blowing

Figure 3. Test of the opacimeter in air/droplet mixing, with and without air blowing

${ }_{18}$ Finally, a verification test was done in order to check the accuracy of the device. A PMMA plate, with known transmissivity equal to $92 \%$ (the complementary part beeing Fresnel's reflexion on the slab surfaces) was located between the emission 
1 and the reception boxes of each of the 16 opacimeters. The transmission measurement was then repeated 10 times, finally 2 providing 160 tests. The exact value of $92 \%$ was found with an average discrepancy of $0.67 \%$ and a maximum discrepancy equal to $1.75 \%$ on the worst test. Again, this shows the confidence which can be brought to the measurements. The wellknown linear behavior of photodiodes warrants that the transmittance response of the opacimeters will be linear across all its $[0-1]$ range.

\section{OPACIMETER APPLICATION IN REAL SCALE FIRE TESTS}

\section{$6 \quad 4.1$ Experimental setup}

7 The opacimetry system was involved in a real scale experiment aimed at producing a smoke layer submitted to a water mist injection. The experimental setup is represented in Figure 4. A detailed description of the setup may be found in [15].

It consists of a room connected to a corridor. The room has an area of $12 \mathrm{~m}^{2}$ and is $2.15 \mathrm{~m}$ high. The corridor is $9 \mathrm{~m}$ long, $101.4 \mathrm{~m}$ wide and $2.40 \mathrm{~m}$ high. An opening (90 cm wide by $20 \mathrm{~cm}$ high) is created on one wall of the room near the floor. It 11 allows providing fresh air in order to avoid potential under-ventilated fire activity especially when the mist is activated in 12 the corridor, because the spray could penalize the air supply possibly provided by the smoke-free layer. There is a $40 \mathrm{~cm}$ high lintel at one extremity of the corridor in order to get a homogeneous smoke layer thickness in the corridor.

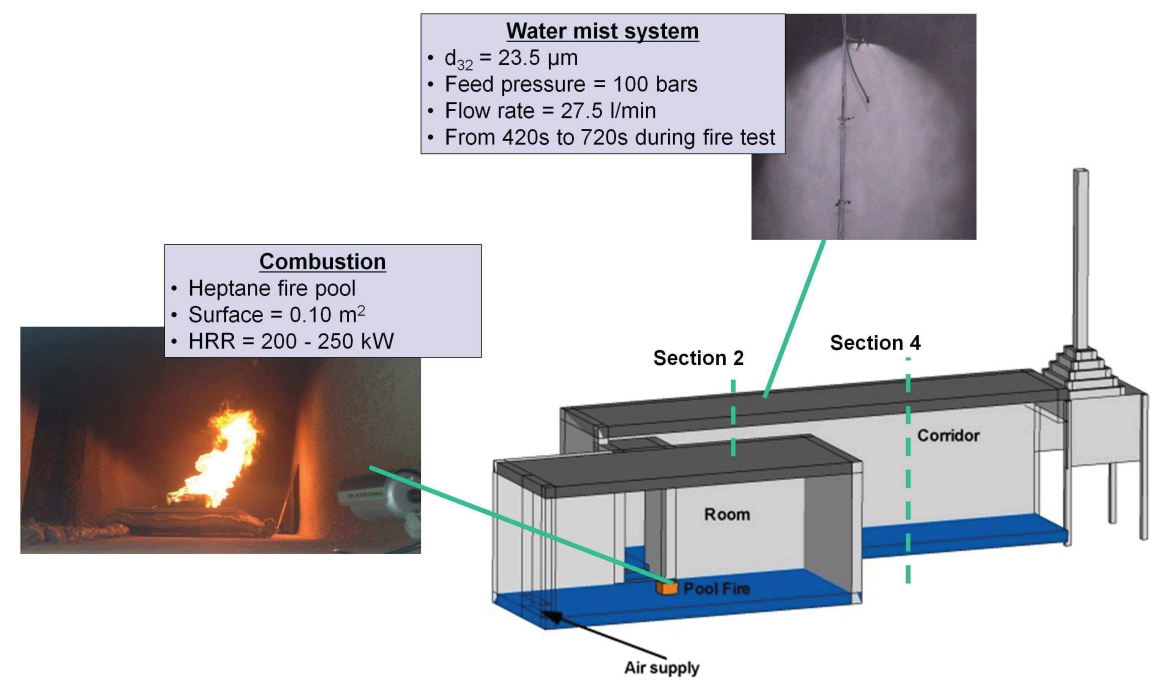

Figure 4. Sketch of the real scale experimental setup

14 The water mist system was installed by a manufacturer (PROFOG). Water mist was sprayed with a nozzle located in the corridor $10 \mathrm{~cm}$ below the ceiling, at $3.50 \mathrm{~m}$ from the extremity near the room. It operated under 85 bars, delivering a water flow rate around 25,2 L/min. The water droplet size was measured with a Malvern diffractometer. The mean Sauter 
1 diameter was found in the range 80 to $100 \mu \mathrm{m}$ at a distance between 0.40 and $1 \mathrm{~m}$ below the nozzle. The water mist 2 system was activated after $420 \mathrm{~s}$ and it operated until $720 \mathrm{~s}$.

3 The smoke flow in the corridor was produced with an heptane pool (with a square surface $0.3 \times 0.3 \mathrm{~m}^{2}$ and $0.1 \mathrm{~m} \mathrm{high}$ ) 4 burning in the room. Five repeatability tests were conducted. The heat release rate (HRR) was found around $250 \mathrm{~kW}$ during the steady-state regime occurring after $240 \mathrm{~s}$. Liquid fuel was used to promote the repeatability and a long steadystate regime, during more than $600 \mathrm{~s}$. The water mist was sprayed during the steady state regime. In other words, the HRR was almost constant when the mist system was activated, when it was spraying and even after mist deactivation.

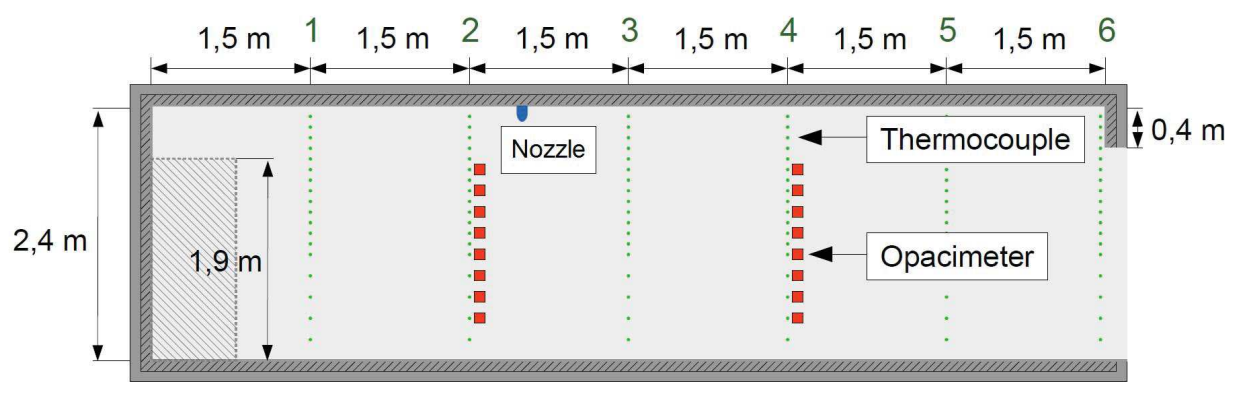

Figure 5. Instrumentation in the experimental setup on mid plane in the corridor

The instrumentation was designed to study stratification and de-stratification of the smoke induced by spray operation, considering both thermal and optical effects. Gas temperature and transmittance were measured in addition to fuel mass. The measurement positions are given in Figure 5. Seven thermocouple trees were used. Six trees were located along the corridor, the last tree was located between the room and the corridor. Each tree involved $18 \mathrm{~K}$-thermocouples with a size of $1 \mathrm{~mm}$ except the one between the room and the corridor which only involved 14 thermocouples since height beneath the ceiling is lower. The space between thermocouples was reduced in the upper part in order to characterize thermal stratification with and without mist. Gas temperature was measured in the central longitudinal plane every $10 \mathrm{~cm}$ between $1 \mathrm{~m}$ and $2.30 \mathrm{~m}$ above the ground, and every $20 \mathrm{~cm}$ below $1 \mathrm{~m}$. Moreover, two opacimeter trees were used close to the water spray, $50 \mathrm{~cm}$ upstream (referred to label 2 in Figure 5) and $2.50 \mathrm{~m}$ downstream (referred to label 4). Each tree involved 8 opacimeters, located from $40 \mathrm{~cm}$ up to $1.8 \mathrm{~cm}$. A distance of $30 \mathrm{~cm}$ between emission and reception was chosen in order to observe attenuations in a range which warrants a good sensitivity. A smaller distance would result in too small attenuation values, while a larger distance would possibly induce too small transmissions and attenuation fluctuations, in relation with some variations in the radiative properties along the path line. 


\subsection{Experimental results}

2 Figure 6 presents the temporal evolution of HRR deduced from heptane pool mass loss rate. The HRR increased rapidly at the beginning, when fire started to burn. The growth rate was important during the first $120 \mathrm{~s}$. Then, the HRR was still growing but at a lower rate. The steady state was reached after $240 \mathrm{~s}$ and lasted till at least $1080 \mathrm{~s}$. The HRR was measured around $250 \mathrm{~kW}$ during the steady-state period. Figure 6 shows that the HRR was not significantly affected by mist at its activation during its operation since no significant HRR variation was observed during this period. This is one of the aim of the configuration: there is no direct action of the droplets on the fire in order to keep the fire burning unchanged. This statement is important, it allows to be sure that the smoke production and combustion chemical reaction remain unchanged during mist operation period. Hence, comparisons can be done between the simple smoke flow before spray activation and the droplet/smoke mixing. In addition, Figure 6 demonstrates the good repeatability of the test. HRR measured in five tests (black curves) were found very similar regarding their evolution and their magnitude. Only the first $900 \mathrm{~s}$ are used in the following study.

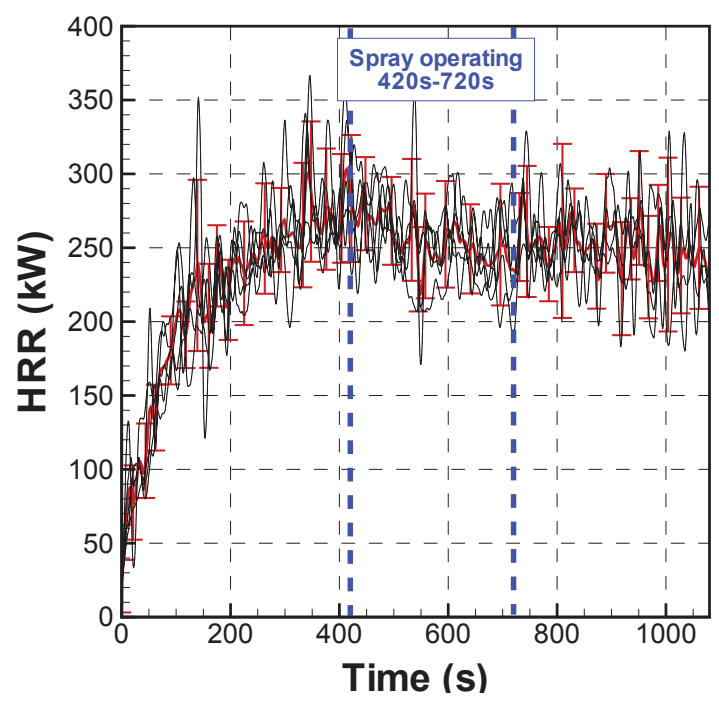

Figure 6. Temporal evolution of HRR deduced from pool mass loss rate. Mean HRR is plotted in red with error bars integrating repeatability. HRR measured in each of the five repeated tests is plotted in black for indication

The experimental data obtained with the thermocouples and the opacimeters are presented in Figures 7 and 8 for the sections 2 and 4 respectively. Temperatures and transmittances are plotted as a function of time. The labels of the curves correspond to the vertical positions of the sensors. The error bars are plotted too. They correspond to uncertainty measurements integrating repeatability with 5 tests performed in exactly the same conditions (e.g. weather, fuel, mist). The measurements for transmittance were also used to identify a characteristic extinction coefficient, based on a simple Beer's law : $\operatorname{Tr}=e^{-\beta . L}$, where $\beta$ is the extinction coefficient and $L$ the path length $(30 \mathrm{~cm})$. The temporal evolutions in 
terms of transmittance or extinction coefficient exhibit the same shape, but with different scale variation.

2 Before mist activation, temperatures increased progressively, while transmittances decreased as the smoke was filling the space below the ceiling. In comparison with gas temperature, transmittance was found more rapidly steady. After only $180 \mathrm{~s}$, it did not decrease anymore and remained at a stable value between 0.8 and 1, depending on the measurement height. During the same time period, gas temperature increased continuously for measurements points located higher than $1.2 \mathrm{~m}$ from the ground. This evolution was attributed to heat transfer phenomena with the corridor walls, because the corridor wall temperature increased due to the exchanges with the hot smoke. The difference in temperature between smoke and walls became smaller with time, decreasing the heat exchanges and finally leading to a stationary step.

As expected, both gas temperature and transmittance values were found to depend on measurement height. Temperature increased with height and transmittance decreased with height. It is a direct consequence of the presence of smoke, hot and more opaque, which was present in the upper part of the corridor. We observed during the tests that the smoke layer was stable in the corridor. The smoke-free layer was found between $1 \mathrm{~m}$ and $1.20 \mathrm{~m}$ high above the ground. Measurements below $1 . \mathrm{m}$ indicated ambient values around $10^{\circ} \mathrm{C}$ and a transmittance equal to 1 . At $1.20 \mathrm{~m}$, the temperature was observed to significantly increase and the transmittance to decrease, thus indicating the presence of diluted smoke. The temperature and the transmittance vertical evolutions provided similar indications on the smoke-free layer. Moreover, vertical profiles of gas temperature and transmittance were found similar at both sections 2 and 4, showing that the smoke layer was almost constant between these two sections. Just before mist activation, on both sections, temperature below ceiling was around $135^{\circ} \mathrm{C} 2.0 \mathrm{~m}$ above the floor while measurements below $1.0 \mathrm{~m}$ indicated the ambient day temperature, $10^{\circ} \mathrm{C}$.

When the spray was activated, at $420 \mathrm{~s}$, a sharp temperature decrease was observed, with a mixing resulting in an homogenization of the temperature distribution, especially downstream the injection point. Upward from the nozzle (section 2) the highest thermocouple still showed a hotter value because the fire was still burning and producing smoke in the corridor. Downstream the nozzle, the mist blocked the smoke flow and the temperature homogeneity was quite perfect. The environment was cooled down to $36^{\circ} \mathrm{C}$ downward the injection. The transmittance presented a more contrasted evolution with the vertical and horizontal positions. The mixing clearly resulted in a decrease in transmission (increase in light attenuation) but the homogeneity was not perfect. There were still some variations especially close to the nozzle (see for example the red square symbols of the curve for the height $1.60 \mathrm{~m}$ in section 2 in fig 7.(b), where the opacimeter possible heterogeneous concentrations in water droplets and soot. Downward from the nozzle, the transmittance fell down to $60 \%$ (for a path line of $30 \mathrm{~cm}$ ). Both temperature and transmittance did not evolve during mist operation, they remained almost at the same value during $5 \mathrm{~min}$. After mist deactivation at $720 \mathrm{~s}$, while the HRR was still at the steady value, all sensors, i.e. thermocouples and opacimeters, were coming back very quickly to their level before spray operation. In particular, transmittances measured below $1.0 \mathrm{~m}$ quickly increased up to 1 indicating a transparent medium. 


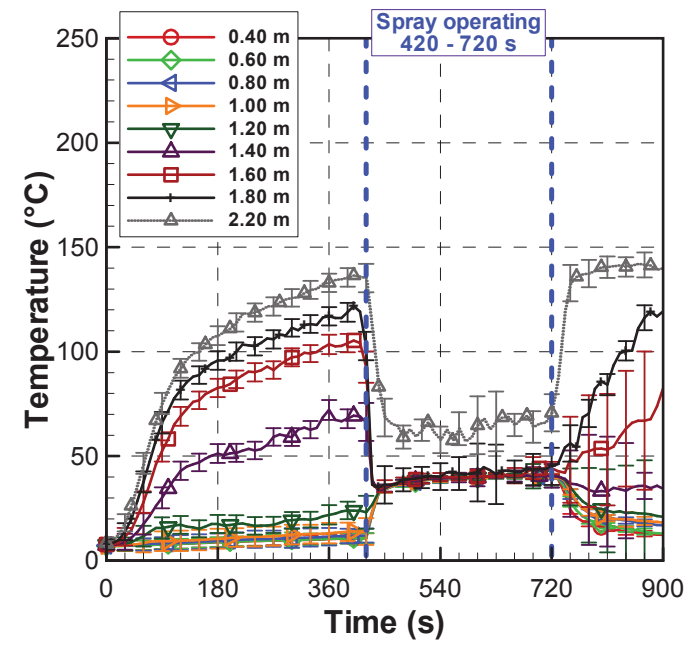

(a) Gas temperature

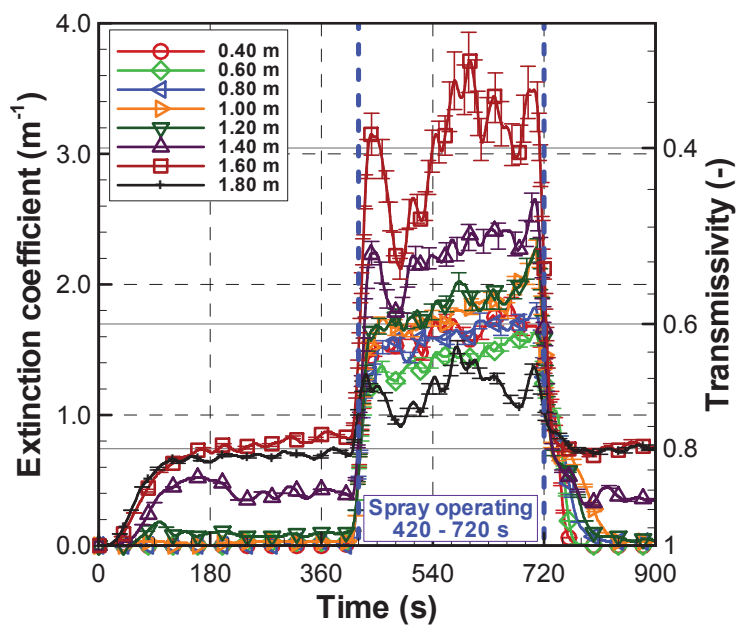

(b) Transmittance

Figure 7. Temporal evolution of gas temperature and transmittance upward from the nozzle (section 2). A double scale in terms of extinction coefficient and of transmittance is provided for the subfigure on the right. The labels refer to the vertical position of the sensor above the ground

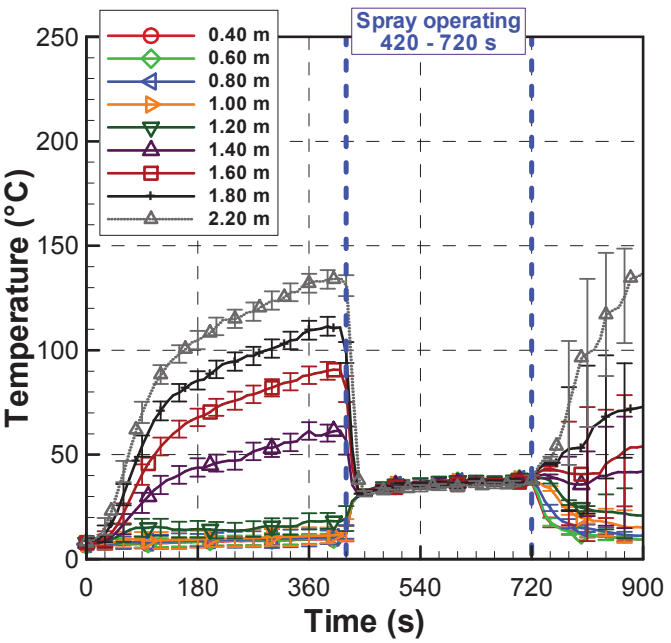

(a) Gas temperature

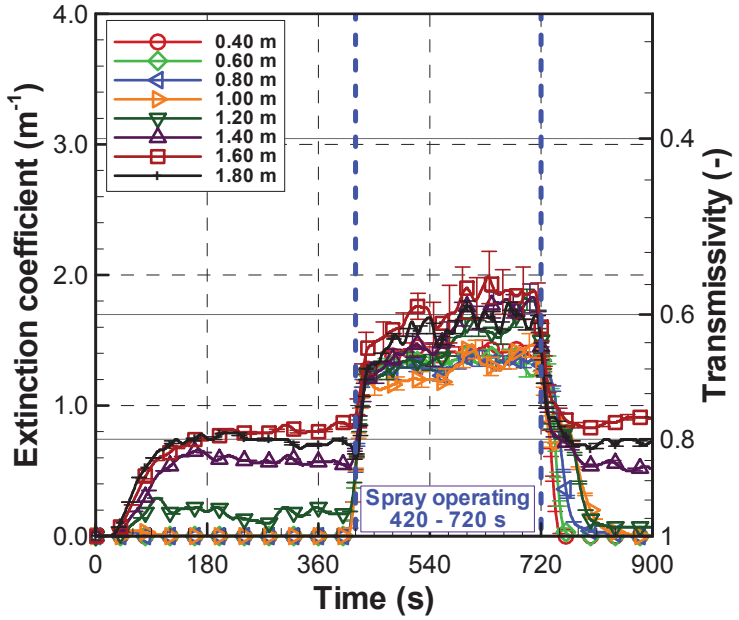

(b) Transmittance

Figure 8. Temporal evolution of gas temperature and transmittance downward from the nozzle (section 4). A double scale in terms of extinction coefficient and of transmittance is provided for the subfigure on the right. The labels refer to the vertical position of the 


\subsection{Smoke stratification study}

2 Vertical profiles of gas temperature and transmittance were also plotted to study the smoke stratification (see Figure 9, the double scale for the extinction coefficient and the transmittance is still provided in Figure 9(b)). Before mist activation, vertical profiles clearly showed the stratified environment. In the upper part, above $1.5 \mathrm{~m}$, gases were hot and more opaque. Temperatures ranged between $100^{\circ} \mathrm{C}$ and $150^{\circ} \mathrm{C}$ and transmittances were found around 0.8 . In the lower part, below $1.0 \mathrm{~m}$, the gas was at ambient temperature and transparent. Between 1.2 and $1.5 \mathrm{~m}$, temperature was increasing with height and transmittance was decreasing. Downward and upward from the nozzle, vertical profiles of gas temperature and transmittance were found similar.

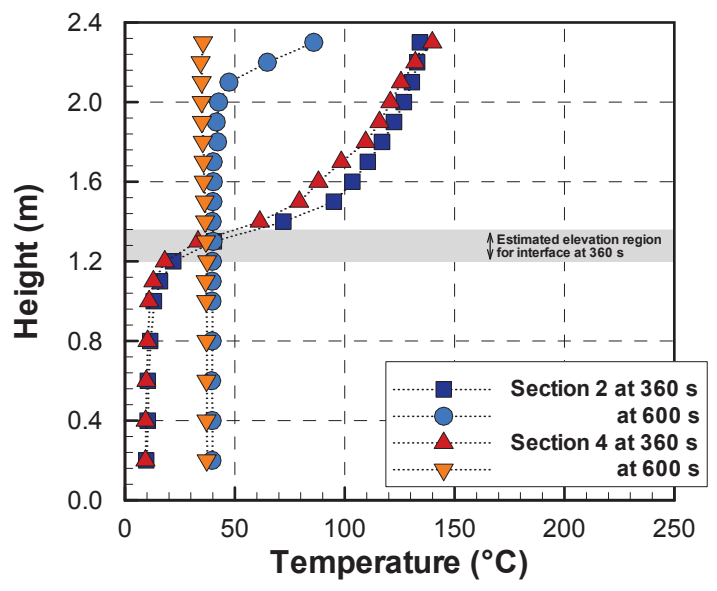

(a) Temperature profile

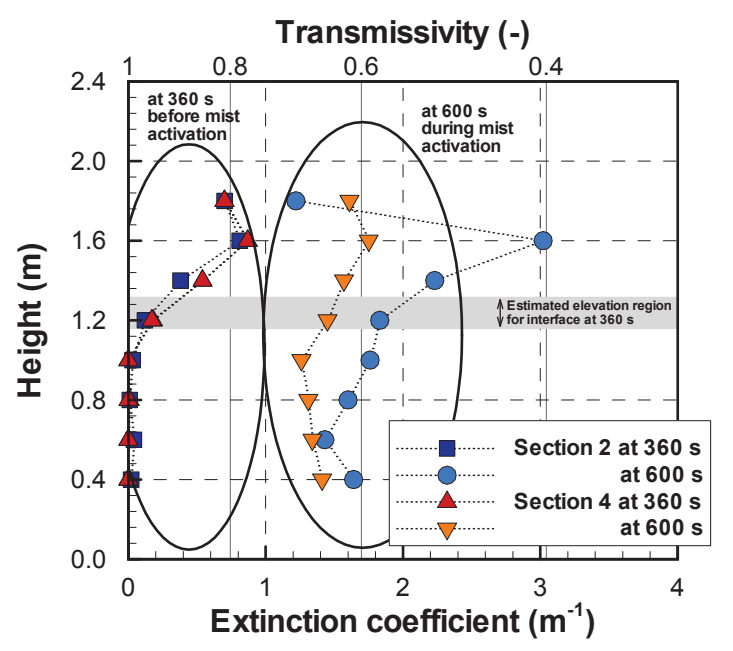

(b) transmittance profile

Figure 9. Vertical profiles for temperature (on the left) and for opacity (on the right, the upper scale corresponds to the transmittance and the lower scale provides the values of the corresponding extinction coefficients). Data are provided downward and upward from the nozzle (section 2 and 4 respectively), before and during mist operation (at 360 and 600 s respectively).

Based on the vertical evolutions, the smoke-free layer height was computed, applying the relationships cited in the introduction. Only the evolutions before mist activation were used. Indeed, the results obtained during mist operation yielded almost flat profiles, which showed that there was no smoke-free layer anymore. In the configuration where smoke stratification was still observed, the idea was to assess if transmittance measurements would give the same evaluation of the smoke-free layer height than temperature measurements. Two categories of relationship can be distinguished, some are based on physical hypothesis such as the models by Quintiere et al. [3] and Janssens and Tran [4], some others are either empirical or mathematical, among them the N\% rule by Cooper [2] and the two models by He et al. [5]. The first models cannot be applied to the transmittance. Actually, it makes no sense to adapt to the opacity problem a quantity 
equivalent to the gas enthalpy estimated by integrating temperature over the height.

2 The N\% rule is based on the maximum temperature recorded over a vertical thermocouple tree. This rule determines the smoke-free layer height (or the elevation at which the interface is considered) as the height at which the temperature is equal to $\mathrm{N} \%$ of the maximum temperature. The approach is preserved to apply it to the light attentuation, which varies as the temperature does (increasing with height). The attenuation $A t$ is defined as the complementary part of the transmittance $\operatorname{Tr}$, such as $\operatorname{Tr}=1-A t$. The interface elevation corresponds to the height at which $\mathrm{N} \%$ of the maximum attenuation is recorded.

s The two models by He et al. are based only on mathematical considerations. They only consider vertical profiles and not the measured quantity. The integral ratio method and the least-squares method are applied here directly to the transmission measurement along the opacimeter trees. Note that the sensor spacing is not the same for the transmittance and the temperature measurement. Therefore, the present calculations were done applying a cubic interpolation on the measurement data in order to smooth the results.

13 Table I presents the calculated values. They are also indicated in Figure 9 as a grey band, which corresponds to the minimum and maximum values obtained for the smoke-free layer height. At measurement section 2, the interface elevation is estimated between 1.20 and $1.38 \mathrm{~m}$ when considering temperatures and between 1.14 and $1.34 \mathrm{~m}$ according to the transmission data. At measurement section 4, the interface elevation is estimated between 1.23 and $1.41 \mathrm{~m}$ based on temperature data and between 1.02 and $1.34 \mathrm{~m}$ based on transmittance data. This 1.02 value evaluated with the integral ratio method seems to us a bit under-estimated when compared to all the results and considering the transmittance and temperature profiles. It was not kept for our analysis. Beside this particular evaluation, it appears that, for each measurement section and each used quantity, the interface elevation is roughly the same. By comparing the values in Table I, it appears that the transmittance tends to give a lower value than the gas temperature in our case. Despite the interpolation, this can be partly attributed to the limited number of used opacimeters and to their locations (the highest opacimeter is located at $1.8 \mathrm{~m}$ whereas the highest thermocouple is at $2.3 \mathrm{~m}$ ). Another reason is that the smoke layer might be cooled in its lowest part, while still being opaque, explaining some differences in the smoke-free layer evaluation.

The opacity data expressed in terms of extinction coefficient may provide a supplementary information on the volumetric fraction of soot particles in suspension in the smoke flow. Applying the often-used approximation $\beta=\frac{5.5 f_{v}}{\lambda}$ with the opacimeter wavelength $\lambda=642 \mathrm{~nm}$ in the present case, yields an estimate for the soot volumetric fraction $f_{v}$. Considering the average value $\beta=0.8 \mathrm{~m}^{-1}$ in the smoke layer before mist activation, a value close to $f_{v}=10^{-7}$ is obtained. A very close value was already reported in [15], based on simulations carried out with FDS. Then, the visibility evaluated from the Jin's relationship [7] $V=3 / \beta$ or $V=8 / \beta$ depending of the object brightness, would be between $3.75 \mathrm{~m}$ and $10 \mathrm{~m}$. Such evaluation cannot be simply applied when the spray is operating because of scattering effects and the need for a dedicated evaluation of the extinction coefficient for the soot-droplet mixing, but this shows that further developments 


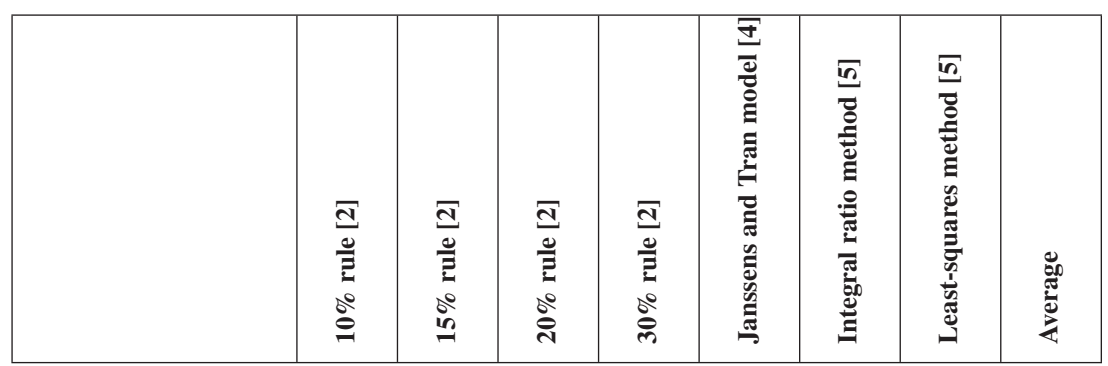

SECTION 2 AT $360 \mathrm{~S}$

\begin{tabular}{|c|c|c|c|c|c|c|c|c|}
\hline Gas temperature & 1.20 & 1.24 & 1.27 & 1.32 & 1.25 & 1.37 & 1.38 & 1.30 \\
\hline transmittance & 1.14 & 1.18 & 1.22 & 1.26 & $\mathrm{X}$ & 1.16 & 1.34 & 1.22 \\
\hline
\end{tabular}

SECTION 4 AT $360 \mathrm{~s}$

\begin{tabular}{|c|c|c|c|c|c|c|c|c|}
\hline Gas temperature & 1.23 & 1.27 & 1.30 & 1.35 & 1.3 & 1.39 & 1.41 & 1.33 \\
\hline transmittance & 1.08 & 1.10 & 1.14 & 1.20 & $\mathrm{X}$ & 1.02 & 1.34 & 1.15 \\
\hline
\end{tabular}

Table I. Smoke-free layer height estimated based on temperature and transmittance measurements

1 could lead to a better knowledge of the smoke-mist layer.

\section{CONCLUDING REMARKS}

2 In fire research, it would be useful in many cases to measure opacity in fire environment. In our particular case, it is important in addition to gas temperature for studying the interactions between water spray and smoke layer to assess the spray impact on people evacuation conditions. In our works mainly based on real scale experiments where thermocouple trees are quite easily used, opacity measurements revealed to be tricky. Indeed, in addition to thermal effects, opacimeters are subjected to soot deposition, water vapor condensation and water droplet deposition. Therefore, a new opacimetry setup required to be developed. A complete device was designed with an optical fiber network aimed at positioning the light source and the detectors outside the smoke/spray environment. The fiber network also allowed the opacity measurement by using only one thermoelectrically stabilized fibercoupled laser diode, instead of one source for each measurement point which would result in a quite expensive device (in the present work 16 sources should be necessary otherwise). This opacimetry device was first calibrated at laboratory scale. The measured signal was checked when the opacimeter was submitted to thermal stresses and then to an air/droplets environment.

13 Then, the opacimetry device was tested in real scale with a smoke layer flowing in a corridor. The smoke stratification 14 was studied in that configuration based on temperature and opacity measurements.

15 As a whole, the obtained experimental data showed a very good behavior of opacimeters despite the hot and wet environment. Moreover, experimental results showed that gas temperatures and opacity both provided similar global 17 information for the stratification before mist activation, at its activation and during its operation. Before mist activation, 
the temperature increased progressively, while the transmittance decreased as the smoke was filling the space below the ceiling. After a few hundred seconds, temperature and transmittance did not evolve anymore. Both temperature and transmittance revealed the presence of fresh air below $1.0 \mathrm{~m}$, free of smoke, at ambient temperature and transparent. Above $1.2 \mathrm{~m}$, temperature significantly increased with height and transmittance decreased with height indicating the presence of hot and opaque smoke

At mist activation, the impact of spray on fire environment (and also on temperature and transmittance) was very fast and concerned a large distance in the corridor. During mist operation, some differences were observed between temperature and transmittance profiles. A perfect homogenization was deduced from the temperatures, while some discrepancies still appeared based on opacimetry data. This probably comes from some discrepancies in the particle concentrations (soot and droplets). This could help identifying some gradients in soot or droplet concentrations. After mist deactivation, all sensors, i.e. thermocouples and opacimeters, came back very quickly to their level before spray operation.

In our research, combining temperature and opacimetry was found very interesting, since opacimetry gives information about the fire environment and soot and/or droplets concentration that thermocouples do not provide. Moreover, opacimetry could provide an input data for the prediction of the visibility or even a tool to identify the particle

\section{ACKNOWLEDGEMENT}

The PROFOG company is fully acknowledged for providing all the setup required for the spray operation.

\section{REFERENCES}

[1] H. Ingason and A. Lönnermark. Large-scale fire tests in the runehamar tunnel - hrr. In Proceedings of the International Symposium on Catastrophic Tunnel Fires, November 2003.

[2] L. Y. Cooper, M. Harkleroad, J. Quintiere and W. Rinkinen. An experimental study of upper hot layer stratification in full-scale multiroom fire scenarios. Journal of Heat Transfer, Vol. 104(4), pp 741-749, 1982.

[3] J. Quintiere. A perspective on compartment fire growth. Combustion Science and Technology, Vol. 39, pp 11-54, 1984.

[4] M. L. Janssens and H. C. Tran. Data reduction of room tests for zone model validation. Fire Safety Journal, Vol. 10, pp 528-555, 1992.

[5] Y He, A Fernando and M Luo. Determination of interface height from measured parameter profile in enclosure fire experiment. Fire Safety Journal, Vol. 31, pp 19-38, 1998. 
[6] D. Drysdale. An introduction to fire dynamics. John Wiley, 2nd edition, 1998.

2 [7] T. Jin and T. Yamada. Irritating effects of fire smoke on visibility. Fire Science and Technology, Vol. 5, No 1, pp 79-89, 1985 .

4 [8] D.J. Rasbach and R.P. Phillips. Quantification of smoke produced at fires. test methods for smoke and methods of expressing smoke evolution. Fire and Materials, Vol. 2, pp 102-109, 1978.

6 [9] V. Babrauskas. The cone calorimeter, in SFPE Handbook of Fire Protection Engineering, 2nd Ed. Society of Fire Protection Engineers, Boston, 1995.

[10] International Organization for Standardization. Fire tests. Smoke generated by building products - dual chamber test. ISO, Geneva, 1990.

10 [11] American Society for Testing and Materials. Standard test method for specific optical density of smoke generated by 11 solid materials. ANSI/ASTM, 1994.

12 [12] E. Guillaume, F. Didieux, A. Thiry and A. Bellivier. Real-scale fire tests of one bedroom apartments with regard to tenability assessment. Fire Safety J., Vol. 70, pp 81-97, 2014.

14 [13] K. T. Paul. Measurement of smoke in large scale fire tests. Fire Safety J., Vol. 5, pp 89-102, 1983.

[14] M. Barakat, J.-M. Souil, C. Breillat, J.-P. Vantelon, V. Knorre and F.-X. Rongère. Smoke data determination for various types of fuel. Fire Safety J., Vol. 30, pp 293-306, 1998.

17 [15] R. Morlon, P. Boulet, G. Parent, S. Lechêne, E. Blanchard, C. Rebuffat, P. Fromy and J.P. Vantelon. Study of de-stratification and optical effects observed during smoke/mist interactions. Fire Technology, Vol. 51, No 5, pp $1231-1248,2015$. 